\title{
TRANSPONDO A DOR EM COR, A LETRA EM PALCO: TEXTOS DE LYGIA BOJUNGA NUNES
}

Marta Morais da Costa *

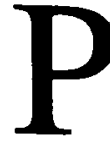

ara quem como Lygia Bojunga Nunes tem com o teatro uma relação apaixonada, não se estranha que cla faça parte de sua obra fíccional ou possa dela sair para o palco.

Declamar, atuar e escrever foram atividades complementares, fruto do que a autora qualifica de uma "recaída teatral" de seu "processo criativo".'

Angélica, de 1975, já incluia no seu corpo ficcional um texto dramático e a história de sua representação, desde a criação da peça, a escolha dos atores, os ensaios até o espetáculo final. O que se apresentava na obra como "ilha", ${ }^{2}$ sem conseguir integrar ou integrar-se harmonicamente no todo da narrativa, cumpria uma necessidade interior da criadora de dar vazão a seu amor e experiência com a arte dramática. A peça inventada pelas personagens Porto e Angélica tinha função ordenadora, mas ficava na dependência do texto narrativo de onde brotava e para o qual apontava. Era como se o tex to dramático estivesse inserido e subordinado à história de uma

*Universidade Federal do Paraná

1 NUNES, Lygia Bojunga. Nós trés: teatro, Rio de Janeiro: Agir, 1990.

2 COELHO, Nelly Novacs. Dicionário critico da literanura infantil / juvenil brasileira: 1882-1982. São Paulo: Quiron, 1983. p. 557. 
companhia teatral. Perdia a independència, o vigor e a especificidade do gênero dramático. Se por um lado abalava a estrutura novelesca, a peça teatral incluida em Angélica indiciava, por outro lado, a ligaçāo profunda de Lygia Bojunga Nunes com a "intimidade que eu tive no passado com o Teatro". ${ }^{3}$

Intimidade essa que ficou exposta em situaçōes, personagens e diálogos dispersos - com alta qualidade - em seus livros posteriores. A força comunicativa, a consistēncia das situaçōes ficcionais e a densidade das personagens presentes em suas narrativas permitem supor uma ligação umbilical com o teatro. Quem teve a feliz oportunidade de assistir à performance de Lygia, transformada no volume Livro, de $1988,{ }^{4}$ conheceu a indissolúvel ligação. Embora o texto falado confessasse seus "casos de amor" pela literatura, o veículo dessa confissāo era simultaneamente uma declaraçāo apaixonada pelo teatro: o veículo incluía-se sub-repticiamente entre os casos de amor.

Antecedentes tāo significativos prepararam o aparecimento, em 1990, de textos teatrais oriundos de duas nartativas: Nós três e $O$ meu amigo pintor, ambas de 1987. A primeira conservou no teatro o título original, mas a segunda foi rebatizada como $O$ pintor. Na orelha da publicação desta última, Lygia Bojunga Nunes explicita a complexa questāo da literatura e do teatro:

Apesar da intimidade que eu tive no passado com o Teatro, desde o meu primeiro livro publicado, venho relutando em ver o meu pessoal, quer dizer, os personagens criados nos meus livros, tomando corpo num palco. Tive sempre a sensação esquisita de que, facilitando a ida deles pro Teatro, eu estaria de cerra forma, traindo a tendencia natural deles todos, que nasceram e cresceram em livro, sem gostar de sair la fora...

Um tempo atrás, o talento e a determinaçāo de Bia Lessa me fizeram rever essa postura - o que me bateu como um verdadeiro ato de amor ao aprendizado teatral.

Este "ato de amor" valeu ao espetáculo encenado no Rio de Janeiro as mais altas premiaçōes, os troféus Mambembe e Molière. Este último, inovadoramente, atribuído a uma peça não destinada exclusivamente a

NUNES, Lygia Bojunga. O pimtor: teatro. Rio de Janeiro: Agir, 1990.

Idem. Livro: um encontro com Lygia Bojunga Nunes. Rjo de Janeiro: Agir, 1988. Idem, O pintor... 
adultos. O reconhecimento da crítica e o sucesso de público apontam para uma transposição da narrativa ao palco muito bem sucedida.

Conhecer miudamente os procedimentos responsáveis por esta transposição é o objetivo do presente estudo. A especulação permitirá, certamente, precisar os caracteres diferenciais de um e outro gênero literário ao mesmo tempo em que interrogará pormenores do ato criador de Lygia Bojunga Nunes.

Comecemos pelo espaço. A conhecida limitação do palco não tem impedido que, atualmente, ele possa espraiar-se por locais múltiplos c amplos, ajudado pela tecnologia e pela aceitação do teatro como ficção inconcebiveis em tempos pretéritos e concepções como a da quarta parede. A transposição do espaço fíccional para o cênico faz supor, portanto, grandes difīculdades. É com agradável surpresa, porém, que nos deparamos com uma quase total semelhança entre o espaço de $O$ meı amigo pintor e $O$ pintor. Percebemos com nitidez o quanto havia de economia cénica no conto e que permitiu a mudança para o palco sem transtomos, inversōes ou invenções.

Os dois apartamentos - de Cláudio e do Pintor - apresentados em poucos aposentos - os quartos, o atelier e as salas - representam as indispensáveis áncoras espaciais da ação. Não têm uma significação mais ampla do que a referencialidade: a ação e os diálogos deveriam ocorrer em algum espaço.

Mesmo assim dois espaços ganham um tratamento diferenciado na peça e no diário. Enquanto neste se dá a confissão do amor infantil do Pintor por Clarice num passeio pela floresta, na peça este ambiente desaparece, substituido pela fala junto à janela de onde se vê a mata. O motivo das cores, entrevistas da janela - o verde principalmente - $\dot{e}$ que introduz a confissão do amor adúltero, propiciada também pela referência ao sonho com Claricebrotinho. Janela, mata e sonho substituem o passeio pela floresta, trazendo para o palco a aumosfera, a afetividade e o desabafo do homem à criança, presentes na narrativa.

Se a floresta desaparece para que o palco assuma sua essência de lugar único de representação do múltiplo, a encenação do imaginário, representada como sonho no diário de $O$ meu amigo pintor, ganha concretitude e maior vigor na peça teatral porque se converte especularmente como espaço de representação da encenação, palco do palco.

No tex to narrativo são dois sonhos que têm como ponto de referência o quadro "Amor". Nele estão figuradas as três paixōes do Pintor: a política, a pintura e Clarice. Num processo de simbiose, próprio dos sonhos, o Pintor 
se converte em figura pintada e aparece sob a forma de fantasma. Este primeiro sonho permite ao menino Cláudio interrogar a morte e sentir perto de si, novamente, o amigo morto. Já o segundo sonho funciona como uma interpretação desmetaforizada das relações-enigmáticas para Cláudio - entre os trés amores do Pintor. Medeia, portanto, os dois sonhos, o processo de decifraçāo da vida do pintor, por ele codificada no quadro "Amor".

$\mathrm{Na}$ peça teatral, Lygia Bojunga Nunes estendeu quantitativa e qualitativamente a presença do quadro. A ele estão reservadas quatro cenas: a primeira, ainda envolta pelo valor do sonho - "num passo estranho de sonho"(P. p. 20) - tem a função de passar à platéia as reflexões de Cláudio a respeito do relógio e da cor amarela, constantes do $1^{9}$ e $2^{y}$ dias da narrativa (MAP, p. 8 a 15). Por uma necessidade de economia cénica, as palavras do texto ficcional ficam restritas a um diálogo rápido, de frases incisivas e densas, reprodurindo a exséncia de situaçōes e reflexōes do garoto. As figuras do quadro servem como pórtico à seqüência do diálogo impossível entre Cláudio e o amigo morto. O destinatário da escrita do menino na obra ficcional era o leitor; no palco ele se multiplica na platéia e no Pintor. $O$ diálogo teatral mostra assim seu mecanismo: existe também para exteriorizar o intimo da personagem, desdobrando-a em vozes alternadas e concretas, apontando para o entendimento da reflexão como uma conversa entre várias vozes.

No segundo momento em que o quadro "Amor" se concretiza como cenário e espaço de representação lica explicitada sua função de tornar tridimensional a mente de Cláudio. As figuras se apresentam ao menino como guias de um espaço-tempo imaginário: "quando vocé quiser sonhar, $\dot{\mathrm{c}}$ só abrir a porta pra gente entrar" (P. p. 41). É a deixa esclarecedora para a terceira apariçāo, desta feita localizada num cenário escancaradamente teatral: "Surge em cena o 'palco de mentira' ou 'minipalco'. Cortina fechada."(P. p. 46).

Sem subterfúgios, o teatro se desnuda. Palco de verdade e palco de mentira vão se entrosar a fim de permitir a Cláudio a compreensão da vida. Agir, pensar e sonhar aliam-se na procura da razāo dos atos humanos determinantes e definitivos.

O recurso metateatral impōe, em primeiro lugar, a oportunidade do espectador receber a confissāo do diário sob a forma dialogada. No palco,

6 A parir deste momento as citaçóes dos textos da autora serão identificadas pelas siglas $P$, de $O$ Pintor, e MAP, de $O$ meu amigo pintor, seguidas do numero da página onde se enconiram. 
vida e sonho se misturam: o menino não sabe representar e o suicida não aprendeu o papel de fantasma. Ante o impasse, o público vaia. É ele quem obriga Cláudio a relatar de maneira intensamente poética a morte do amigo:

CLÁUDIO - Pra ele a coisa que tinha mais cor de morte era nevociro (...) E um dia desses, fez um nevoeiro forte toda a vida. O Pintor espiava pela janela do apartamento dele, só via aquele nevociro tapando tudo que é cor e falava feito costumava falar: PINTOR - Hoje tá fazendo um pouco de vontade de morrer. CLÁUDIO - Foi um nevoeiro comprido, que durou a tarde toda e a noite inteirinha tambím. A toda hora o Pintor espiava na janela. E nada da vontade de morrer acabar. Foi por isso que ele se enganou. Achou que a vontade nunca mais ia passar e entào resolveu matar a vontade. Tipo do engano sem jeito: no dia seguinte amanheceu um céu azul bonito mesmo. (P. p. 50-1)

Respcitados pequenos cortes, o mesmo texto havia aparecido em $O$ mel amigo pintor (p. 26,7), bem como lá está a estrutura básica da cena. Esta transposição evidencia claramente a concepção dramática e o domínio do diálogo coloquial, pronto para o palco, de Lygia B. Nunes. Esta cena comovente, encoberta poeticamente pelas metáforas da cor indicia outro procedimento marcante desta obra da autora: o tema da morte ganha bele $z a$ e poeticidade sem perder a contundéncia e o senso do irreversivel. A cena aponta para caminhos inesperados na compreensão das razōes que levaram o artista ao suicídio. Caminhos traçados/desenhados pelo menino Cláudio na sua ảnsia de compreensão da vida. Neste caminho da cor, vida e morte se completam harmoniosamente. Quem vive da cor nela morre. E encena a exposição dos motivos e o desencontro com o papel, na cabeça e no palco, locais de questionamento.

lgual surpresa é reservada para a descoberta, no ato de comparar os dois textos, como a cena teatral estava inteira no relato ficcional. As pequenas alteraçōes serviram para evidenciar o conhecimento de carpintaria teatral da escritora. Por exemplo, na inente da criança "a cortina cra cor-desaudade (...) o palco cra todo da cor da cortina, e quem sentava no teatro licava então só olhando para saudade c mais nada" (MAP. p. 26). A imaterialidade da cor do palco e da cortina é substituída na peça por um rápido diálogo entre Cláudio e vozes do público, eın que o menino confessa sua recusa em acreditar na morte do amigo e sua vontade de preferir a lembrança dele enquanto vivo. O diálogo é mais longo e menos poético do 
que a descoberta daquela "cor-de-saudade" mas nāo deixa de ser revelador quanto ao estado de ánimo da personagem.

A quarta e última imagem cénica do quadro "Amor" se localiza no instante em que Claudio procede ao inter-relacionamento de fatos e sensaçōes para, enfim, compreender o suicidio do pintor. Esta cena em seu inicio nāo está presente no texto ficcional:

Cláudio surge afobado, vestido e mascarado do mesmo jeito que as Figuras. A roupa arrasta de um jeito que, pra correr, ele tem que "levantar as saias". O efeito é cómico. Se cola às Figuras pra passar tambem a fazer pane do quadro. O efeito desse "quadro vivo" também é engraçado com ele assim tão pequeno e elas tiio altas.

(...)

CLAUDIO - (vai tirando a máscara devagarinho. Cochicha em tom de mistirio pro Pintor, botando a mão do lado da hoca pra elas nào ouvirem...) Ei! (O Pintor olha pra cle.) Não diz pra clas. viu? mas eu vim morar aqui no leu quadro pra descohrir tudis. (P. p. 57-8)

Bela imagem da importancia da arte: as razóes da vida e da morte do artista encontram-se em sua própria obra. Ao mesmo tempo, a dimensāo do desejo do menino de aparecer como a quarta paixāo do Pintor nada mais expressa do que a concretização das palavras do artista ao declarar-lhe afeição: "Cada dia eu gosto de vocé de um jeito. E se a gente junta tudo que é jeito, vè que gosta bem grande, vé que é amor." (P. p. 17)

Cláudio compreende, pois, que se o quadro se intitula "Amor" ele tem um lugar ali. Mais do que isso, só entenderia a morte do amigo compreendendo sua vida, suas paixöes:

CLÁUDIO - Será que um antista pode amar tanto o trabalho dele (...) que, se o trahalho não tem vida, ele tambim não quer mais tor? (P. . . 61)

Se o quadro - espaço do imaginário e da arte - poderia lhe dar alguma resposta, Cláudio não demora a constatar a falsidade dela. As Figuras haviam-no aconselhado a separar a interrogação da imagem do amigo, mas o menino não tardou a descobrir que, como no álbum de imagens que recebera de presente do Pintor, a verdade c a vida só poderiam ser encontradas na fusão de tudo: 
(...) eu penso nele inteiro, quer dizer: cachimbo, tinta, por què, gamào, flor que ele gostava, morte de propósito, por quê?, relógio hatendo, blusão verde, tudo bem junto e misturado (...) Acho até que se eu continuo gostando de cada porquè que aparece, cu acabo entendendo um por um. (P. p. 64)

Palavras idênticas se encontram no parágrafo final do diário de Cláudio. Desta forma, o espaço do quadro c do "palco de mentira" acabam por se integrar, formando uma só e completa realidade para o protagonista: este é o resultado de sua interrogação da vida - e da morte.

A dinamização e alternância dos espaços representados no palco se concretizam através de dois recursos: o primeiro, mais realista, pelo deslocamento dos atores - personagens e o segundo, pela iluminação - recurso péculiar às artes cênicas.

A luz é usada em $O$ pintor em diferentes circunstâncias, apontando para diferentes significaçōes. Toda vez que a rubrica se refere à iluminação é porque visa atingir um objetivo outro que não o de deixar a cena às claras. Assim, ela é esbatida nas cenas de revelação da morte do Pintor para, a seguir, iluminar a "orgia de cores" do apartamento do suicida, criando o contraponto entre morte e vida. A passagem de um espaço a outro vai sendo marcada pela luz que dirige assim o olhar do espectador, indicando a sequiencia das cenas, até o momento final quando "O palco se apaga" (P. p. 64)

Quanto às personagens, algumas pequenas alterações foram processadas. O colega que servia de confidente a Cláudio no episódio do coração amassado foi substituído por Rosário, sua vizinha, permanecendo imutável a seqüència da ação e seu significado. $O$ papel da familia e do síndico foi acrescido, principalmente o da Irmã para favorecer as cenas de mexericos e de confidências. A concentração de personagens, jả existente no texto narrativo favoreceu a transposição que, por indicação da autora, ainda reduz. o número de atores ao permitir que as Figuras sejam interpretadas pelas mesmas atrizes que fazem a Irmã, a Mãe e Janaina.

Ganham destaque na peça teatral Cláudio c o Pintor. Ao se comparar o discurso direto do adulto no diário do menino e os diálogos da peça, verifica-se o tratamento privilegiado da personagem do artista. Alteração de fácil entendimento: o gênero dramático apóia-se fundamentalmente na arte do ator, que tem nas falas seu meio de expressão mais fértil. Na peça, a inexistència de um narrador constante e confessional como o do diário de $O$ men amigo pintor obriga o dramaturgo a semear entre as demais personagens 
pensamentos, retrospectiva, sensaçōes e sentimentos em forma de diálogos para que a história possa se tornar compreensivel para o público do teatro.

E ć exatamente no que respeita o diálogo que é possivel detectar a visão teatral de Lygia Bojunga Nunes embutida no texto narrativo. As falas das personagens de $O$ mell amigo pintor aparecem na maioria dos diálogos de $O$ pintor reproduzidas literalmente. São raros os exemplos de uma transposição assim direta na alteração de narrativas para dramas. Esta constatação ajuda a entender a razāo pela qual se afirma que as personagens da obra ficcional de Lygia são "vivas". De tal forma a escritora domina a realidade lingüistica do discurso ficcional que ele pode ser transposto, sem perda de sua vivacidade, para um estado de real enunciação. A oralidade presente na ficçāo, e necessária no teatro, pertence, pois, às grandes qualidades da escritora. Vejamos alguns exemplos.

\footnotetext{
Mase o religio?

De noile, quando eu fui domir, fiquei esperando, esperando, esperando.

Nada. So aquele hranco todo; eu nunca pensei que silencio fosice assim tāo branco. E aí, sim, eu vi mesmo que o meu amigo tinha morrido e que branco doja mais que preto, amarelo nem se fala! doia mais que qualquer cor.(MAP. p. 10)
}

Na peça teatral ficou assim:

CLÁUDIO - E ai...quando cu fui dormir...eu fiquei esperando,. esperando... E nada.

PINTOR - Ele nào hatia mais nada?

CLÁUDIO - Nada. Só aquele branco todo.

PINTOR - Silincio é uma coisa tão branca, nãu é?

CLÁUDIO - E foi só ai que eu vi mesmo que vocè tinha morrido, e que branco doia mais que preto, amarelo nem se fala! doia mais que qualquer cor. (Os dois ficam olhando pra frente, sentindo a dor do silencio.) (P. p. 25)

Em outro exemplo, quem cotejar a cena do "palco de mentira" (P. p. 47-51) e a seqüencia do sonho de Cláudio (MAP. p. 25-7) verificara a reprodução quase total do segundo no primeiro. As diferenças licam por conta das observaçōes do narrador transferidas às rubricas: "O público desatou de novo a bater pé. (MAP, p. 26) toma-se "(O público, isto $\dot{e}$, as 
vozes na platéia desatam a reclamar: Essa peça vai ou não vai começar?)" (P. p. 48).

Algumas cenas centralizam vários momentos dispersos no texto narrativo. Isto acontece com a primeira cena de $O$ pintor. Para ela convergem fragmentos dos três primeiros dias do diário de Cláudio. Entende-se esta confluência pela necessidade de informar os espectadores a respeito do fato desencadeador da ação dramática: o suicídio do pintor e as versões sobre a causa de sua morte.

Essa mesma diretiva em busca da síntese é exercida competentemente em outras cenas da peça, em especial quando contracenam Cláudio e o Pintor.

A leitura do diário mostra freqüentes digressōes reflexivas do narrador: elas fazem parte da natureza desse tipo de narrativa que soma o factual e o reflexivo. Ora, essas digressões interrompem a dinâmica da ação e alteram o ritmo do espetáculo se mantidas na encenação teatral. Elas estão diretamente relacionadas com a manifestação de ações interiores e constituem desafios à competência dramatúrgica dos escritores. Exigem transposição para outros códigos do espetáculo, não-verbais, que possam conservar em termos cênicos, intenções e sentido do tex to original. O melhor exemplo dessa passagem é a conversão do sonho em "palco de mentira": o onírico se concretiza enquanto cenário e enquanto uma encenação.

A procura da sintese, caracteristica do gênero dramático, chega a bons resultados como se pode ver a seguir:

(...) quando eu olho pra uma coisa eu me ligo logo é na cor.

(...)

Um dia o meu amigo me disse que eu era um garoto com alma de artista, e me deu um álbum com uns trabalhos que ele tinha feito em aquarela, tinta a óleo e pastel. Disse que tinha arrumado os trabalhos no álbum pra eu entender melhor esse negócio de cor. Nas primeiras páginas só tinha cor. Quer dizer, no princípio nem cor tinha: era só branco e preto; depois começavam as cores: amarelo, azul, vermelho, e depois essas três cores iam se misturando para formar uma porção, nuns desenhos que às vezes eu gostava e outras vezes não.

O meu amigo me disse que quanto mais a gente prestava atençāo numa cor, mais coisa saja de dentro dela. Eu fiquei olhando pra cara dele sem entender. Não entendi mesmo aquela história de tanta coisa ir saindo de dentro de uma cor. (MAP. p. 8) 
Este fragmento se reduz a partes pequenas de duas falas do Pintor na quarta cena da peça:

PINTOR - Eu fiz um álbum pra te mostrar melhor esse negócio de cor que a gente tem conversado. (...)

PINTOR - (...) quanto mais eu olho pra essas cores, mais coisa vai saindo de dentro delas.

CLÁUDIO - (Duvidando) Hm... (O Pintor olha pra ele) Esse negócio de tanta coisa ir saindo de dentro de uma cor... isso não é birutice de pintor? (P. p. 15-6)

Mas o texto cênico nāo recebeu apenas a sintese de fragmentos narrativos. Ganhou espaços - como o "palco de mentira" - falas explicativas, como a lição de arte modema, em que são citados Matisse e Tomie Ohtake.

Um olhar crítico sobre os dois textos consegue descobrir como se mantém neles a indagação constante e angustiada do jovem Cláudio a respeito da vida e da morte, sem infantilismo nem desregramentos dramáticos. Foi mantida de maneira admirável toda a ambientação simbólica que valoriza o papel da arte como um caminho para o entendimento da existência, com toda sua dor e suas alegrias.

A cor, como um código de expressão dos momentos mais significativos da vida humana, parece ter sido a lição mais preciosa que Cláudio só conseguiu aprender após uma sofrida trajetória, em que a perda foi inicio e interrogaçāo. O difícil obstáculo de constantes flashes-back foi superado de maneira brilhante pelos recursos da iluminação, pela presença do leitmotif do jogo de gamão, pela criaçāo do palco dentro do palco, pelas cenas curtas e amarradas entre si pela presentificaçāo constante de Cláudio.

Assim, reduzindo, cruzando, servindo-se de outros códigos do espetáculo, procedendo sempre a uma transposição que visa obter a eficácia cênica, Lygia Bojunga Nunes realizou uma criaçāo que aponta em duas direções: em primeiro lugar, confirmou a construção dramática do texto narrativo, o que lhe permitiu respeitá-lo integralmente na peça teatral; em segundo lugar, demonstrou pleno conhecimento da carpintaria teatral, criando um texto de grande vigor e poeticidade, que the valeu, merecidamente, o prêmio Molière. 


\section{RESUMO}

A transposiçāo do texto narrativo em forma de diário $O$ meu amigo pintor para a peça teatral $O$ pintor, ambos de Lygia Bojunga Nunes, enseja algumas especulações analíticas, visando avaliar os procedimentos criativos utilizados nas alterações e na permanència de componentes textuais.

\section{RÉSUMÉ}

La transposition du texte narratif en forme de journal $O$ meu amigo pintor en pièce dramatique $O$ pintor, l'un et l'autre de Lygia Bojunga Nunes, nous permet quelques spéculations analytiques avec l'objectif $\mathrm{d}^{\circ}$ estimer les procédés créatifs employés aux altérations et à la permanence de leurs éléments textuels.

\section{REFERÊNCIAS BIBLIOGRÁFICAS}

COELHO, Nelly Novaes. Dicionário crítico da literatura infantiljuvenil brasileira: 18821982. São Paulo: Quiron, 1983.

NUNES, Lygia Bojunga. Angélica. Rio de Janeiro: Agir, 1975. . Livro: um encontro com Lygia Bojunga Nunes. Rio de Janeiro: Agir, 1988. . Nós três. Rio de Janeiro: Agir, 1987. Nós três: teatro. Rio de Janeiro: Agir, 1990. O meu amigo pintor. Rio de Janciro: Agir, 1987. . O pintor: teatro. Rio de Janciro: Agir, 1990. 